\title{
Luxo x Popular: análise de produtos da Coleção Karl Lagerfeld for Riachuelo
}

Ana Cláudia de Abreu

Mestranda, Universidade Estadual Paulista - UNESP / a.abreu.ana@gmail.com Orcid: 0000-0002-4915-8197/http://lattes.cnpq.br/9597295518009698

Marizilda dos Santos Menezes

Doutora, Universidade Estadual Paulista - UNESP/ zilmenezes@uol.com.br

Orcid: https://orcid.org/0000-0003-4242-0698/http://lattes.cnpq.br/4760173147289270

Mônica Cristina Moura

Universidade Estadual Paulista -UNESP/ monicamoura.design@gmail.com

Orcid: 0000-0002-9994-6669/http://lattes.cnpq.br/5034451123099716

Enviado 30/06/2018 /Aceito 15/08/2018 


\title{
Luxo x Popular: análise de produtos da Coleção Karl Lagerfeld for Riachuelo
}

\begin{abstract}
RESUMO
Esse artigo apresenta uma breve contextualização do cenário contemporâneo brasileiro e suas particularidades que refletem nas estratégias de mercado, para atender o usuário que busca individualização por meio de produtos. Neste âmbito, é abordado as redes populares de fastfashion que estabelecem parcerias com marcas de luxo, para facilitar o acesso das informações de alta moda, aos que não possuem condições de adquirir um produto desta categoria. Mais especificamente, o foco deste artigo é a parceria entre Karl Lagerfeld e a Riachuelo, que em 2016 lançou uma coleção de moda com elementos que remetem ao estilo pessoal do estilista e da marca Chanel. Deste modo, o objetivo é compreender os signos do criador e os possíveis significados gerados pelos indivíduos ao adquirirem os produtos. Para isso, foi utilizado a abordagem qualitativa, a pesquisa bibliográfica e a descritiva para sustentar a análise de três looks da coleção. Os parâmetros que guiaram as observações foram os níveis de complexidade objetivo/subjetiva de Bomfim (1997). Como resultado foi constatado signos pessoais referente ao criador $e$ ao universo de luxo que os circunda.
\end{abstract}

Palavras-chave: cenário contemporâneo brasileiro; produtos de moda; Karl Lagerfeld for Riachuelo. 


\title{
Luxury vs. Popular: analysis of Karl Lagerfeld for Riachuelo Collection's
}

\begin{abstract}
The article presents a brief contextualization of the Brazilian contemporary scenario and its peculiarities that reflect the market strategies, to attend the user who seeks the individualization through the means of products. In this context, it is approached as fast-fashion networks that establish partnerships with luxury brands, to facilitate access to high fashion information, for those who can not have access to an item of this category. More specifically, the focus of this article is a partnership between Karl Lagerfeld and Riachuelo, who in 2016 launched a fashion collection with elements reminiscent of the stylist's personal style and the Chanel brand. The objective is to understand the signs of the creator and the possible meanings generated by the individuals when acquiring the products. For this, a qualitative approach was used, a bibliographical research and an analysis to support a three-look analysis of the collection. The parameters that were cranes were the objective / subjective wealth levels of Bomfim (1997). As a result, personal signs have been created in relation to the creator and the universe of luxury that surrounds them.
\end{abstract}

Keywords: brazilian contemporary scenario; fashion products; Karl Lagerfeld for Riachuelo. 


\section{INTRODUÇÃO}

O cenário contemporâneo brasileiro é marcado por transformações em esferas culturais, políticas, socioeconômicas e tecnológicas que contribuíram para ampliar o campo do design, proporcionando novas formas de projeto, produção, relacionamento e comunicação. Uns dos pontos relevantes é a globalização devido o acesso à informação, possibilitando uma determinada classe social compreender sobre um específico segmento de produtos que distância da sua realidade econômica. Moura (2015b) aponta que estas mudanças impactaram o modo de consumo dos usuários, pois passaram a buscar objetos que retratam seus hábitos e estilo de vida como forma de diferenciação na sociedade e, em uma esfera simbólica muito mais demarcada.

Nesse contexto é possível identificar estratégias de mercado para atender este perfil de consumidores e uma delas está relacionada com a ascensão econômica das classes populares. Em vista disso, as redes de fast-fashion buscam parcerias com marcas de luxo, com o objetivo de atender aos desejos dos usuários em adquirir um produto de uma conceituada marca, por um preço acessível.

Pautado nessas observações, o presente artigo tem como objetivo compreender os signos articulados por Karl Lagerfeld em uma coleção para a rede de fast- fashion Riachuelo e, os possíveis significados gerados pelos indivíduos ao adquirirem os produtos da coleção.

Para o devido cumprimento, a metodologia adotada é de caráter qualitativo com revisão bibliográfica que aborda assuntos sobre design contemporâneo, produtos de luxo, populares e parcerias entre rede de lojas e estilistas conceituados. Por fim, foi selecionado três looks da coleção para serem analisados segundo os parâmetros de 
complexidade objetivo/subjetiva de Bomfim (1997). Para esta etapa foi utilizado o método descritivo que busca ressaltar as características do objeto de estudo com base nas variáveis.

Neste caso o presente trabalho possui três objetos de estudo, ou seja, três looks da coleção e as variáveis são os níveis de complexidade objetivo/subjetiva de Bomfim (1997).

\section{O CENÁRIO CONTEMPORÂNEO BRASILEIRO DE PRODUTOS DE LUXO X POPULAR}

Neste tópico, o objetivo é apresentar algumas mudanças de consumo no cenário contemporâneo brasileiro e a diferença entre produtos de moda da categoria de luxo e populares. Para isso, foi preciso contextualizar a contemporaneidade e identificar fatores que mudaram $o$ perfil de consumo dos brasileiros, além do papel do designer como gerador de conceitos.

A contemporaneidade no Design e na Moda torna- se evidente no Brasil a partir dos anos 1990, devido a marcos que ocorreram no mercado nacional, tais como a globalização, a valorização de culturas locais, a rápida circulação de informação e conhecimento por conta do desenvolvimento tecnológico e digital. Esferas políticas e socioeconômicas também contribuíram para a alteração do cenário, interferindo na capacidade de compra dos indivíduos. Por conta da popularização de crédito e do microcrédito, levando várias pessoas adquirirem bens de várias categorias para conquistarem uma posição na sociedade (MOURA, 2015b, p.2).

Para Moura (2015a) os produtos são responsáveis pela individualização e transmitem além da praticidade, o conforto, prazer e status. Para Feathersthone (1995), esta característica denomina- se estetização da vida cotidiana, na 
qual há um rompimento entre o real e a imagem, prevalecendo a representação emocional e afetiva que os produtos transmitem. Baudrillard (2008) discute que o caráter simbólico dos objetos transcende o funcional, uma vez que a sua praticidade não está relacionada à funcionalidade, mas a de significação. Portanto, os objetos estão ligados diretamente ao homem e são portadores de informações que mediam as relações humanas.

Featherstone (1995) apresenta pontos que definem esta estetização da vida cotidiana, e uma delas refere-se às relações pessoais que são construídas a partir da estética. Por isso cada sociedade cria um estilo de vida e personifica seu entorno com objetos e hábitos pessoais, que traz associações com a imagem que procuram transmitir. Isto posto, estas características são intensificadas com as tecnologias digitais, que contribuíram para ampliar o campo do design, possibilitando a busca de informação e troca de conhecimentos entre diferentes classes sociais. Um exemplo é o acesso ao conteúdo de objetos de luxo que desperta desejo de compra nas classes que consomem produtos populares.

O termo luxo mede a riqueza e a classe social de um indivíduo e está relacionado a dois conceitos: luxo tradicional e contemporâneo. O primeiro está ligado ao materialismo, ou seja, um produto exclusivo com caráter de fazer o usuário ganhar destaque na sociedade. Já o segundo é subjetivo e depende do sensível que vem de encontro aos aspectos simbólicos. Por fim estas duas categorias caminham juntas e se complementam para atender a expectativa dos usuários frente aos produtos de luxo no Brasil (DINIZ, 2012).

Neste contexto Passareli (2010) apresenta três características que devem ser encontradas nos produtos de luxo. A primeira é a beleza, que diz respeito à percepção do 
usuário em relação ao produto. A qualidade total, considerada como eficácia desde a etapa do projeto, passando pela configuração com materiais nobres e detalhes minuciosos. Por último a tradição das empresas, que carregam uma história e constroem uma relação emocional objeto/usuário a longo prazo.

Estes apontamentos são respostas ao preço superior e as peças limitadas e controladas, para o consumidor sentir-se privilegiado.

Assim como o mercado de luxo o de consumo popular também possui suas particularidades. Yaccoub (2011) aponta que este grupo é composto por potenciais consumidores de menor poder aquisitivo e, que não precisam estar inseridos em um nível econômico mais alto para continuar comprando em momentos de crise. Além disso ressalta que o fator renda é um dos indicadores para estabelecer uma classe social e, não pode ser vista como um critério para definir posição social. Um exemplo são os parcelamentos, já que no momento da compra não é possível identificar se o consumidor faz parte de um determinado grupo ou está endividado.

A FGV realizou uma pesquisa sobre esta classe denominando- a como a "nova classe média" ou "classe $C$ ", na qual está acima da $D$ e $E$ e abaixo da $A$ e $B$, representando $52,67 \%$ da população. Além disso revela que essas pessoas buscam manter os nomes "limpos", para garantir acesso aos créditos e adquirem aos poucos objetos que simbolizam status, beleza e conforto (YACCOUB, 2011).

Uma mudança significativa no padrão de consumo desta classe, foi a informação de moda que está ligada às mudanças do contemporâneo. Para atender esta demanda o setor da moda propõe o modelo empresarial fast- fashion, que busca suprir as necessidades com rapidez por meio de produtos acessíveis e com tendências atualizadas. 
Nesta configuração de serviço, Sabino (2007) cita que as empresas de moda rápida estabelecem estratégias para multiplicar as vendas e aumentar o valor simbólico dos produtos, por meio de parcerias com criadores renomados no mercado. Messias (2016) complementa informando que os produtos ganham valor estético e simbólico, devido o desenvolvimento com métodos criativos e exclusivos de grandes designers. Além da comunicação nos pontos de venda como expositores, vitrinas, catálogos e sacolas que fortalecem o vínculo da parceria, contribuindo para valorização da coleção.

Em 2004, a marca sueca de fast- fashion $\mathrm{H} \& \mathrm{M}$, desenvolveu uma coleção com o estilista alemão Karl Lagerfeld - diretor criativo da grife de luxo Chanel, como estratégia para valorizar os produtos de moda rápida. A parceria foi um sucesso e logo em seguida fechou contrato com outras grifes que possuem uma forte representatividade no mercado da moda como Stella McCartney, Roberto Cavalli, Lanvin e Versace (MESSIAS, 2016).

No Brasil a rede de moda rápida Riachuelo, aderiu à ação de aproximar peças de luxo as de fast-fashion, para atender a este consumidor que busca valores simbólicos em produto de moda. Portanto, estabeleceu parcerias com grifes de luxo como a italiana Versace em 2014 entre outras marcas, na qual os modelos são desenvolvidos em colaboração e produzidos internamente para reduzir o custo de produção (SOCIEDADE BRASILEIRA DE VAREJO E CONSUMO, 2016).

Em abril de 2016, a Riachuelo apresentou na edição de Verão 2017 do São Paulo Fashion Week- SPFW, uma coleção assinada pelo estilista alemão Karl Lagerfeld com 75 produtos compostos por signos que remetem às características do estilo pessoal do estilista e da marca francesa Chanel, que está a frente da direção criativa (FFW, 2016). 
Por fim, para compreender os signos inseridos nos produtos da coleção, torna- se necessário analisá- los e verificar a sua relação com o universo do criador.

\section{ANÁLISE DOS LOOKS DA COLEÇÃO KARL LAGERFELD FOR RIACHUELO}

Para analisar a coleção foram selecionados três looks que representam o conjunto total dos produtos, por meio dos recursos visuais como cores, formas, texturas e volumes. Toda leitura foi realizada no portal Fashion for Ward- FFW, site oficial do evento de moda brasileira - São Paulo Fashion Week, onde foi possível obter acesso às imagens e aos textos referentes à coleção.

A análise foi estruturada segundo os níveis de complexidade na relação objetivo/subjetiva apresentados por Bomfim (1997), no qual discute que a figura é o resultado do processo de configuração e, estabelece relação entre sujeito e objeto, por meio de um conjunto de aspectos que podem ser identificados no âmbito sensorial, imagético e representativo. Para complementar Bomfim (1996) considera que o objeto é a união da figura que representa sua essência por meio de recursos materiais, forma, textura, cor entre outros aspectos que buscam atender as necessidades e aspirações do sujeito, além das funções do objeto.

Cardoso (2012) apresenta uma visão semelhante a de Bomfim (1997 e 1996), e considera que a qualidade sensorial do objeto vai além de um plano de visualização representado pela junção de elementos de superfície, volume, contorno e espaço. Logo, o indivíduo têm a capacidade de criar significados e fazer associações através desses elementos visuais. Contudo, a relação do objeto com o sujeito se torna mais intensa do que a sua funcionalidade. 
Para Bomfim (1996, p.17) esse processo é denominado morfologia dos objetos e, estuda as formas de uma figura e seus significados. Assim considera que em um produto é possível atribuir inúmeras funções "mesmo que distintas daquelas para as quais o objeto foi originalmente criado".

Neste âmbito, para solucionar um problema, o designer faz uma profunda pesquisa sobre o usuário, os aspectos tecnológicos, mercadológicos e outros fatores que antecedem a geração de alternativas para escolher a melhor solução. Mas por outro lado, quando o usuário adquire o produto, o mesmo passa a ter vida própria por conta do processo de utilização. Isto ocorre porque os objetos se tornam extensão do indivíduo (BOMFIM, 1997).

Esse processo é previsto pelo designer na fase de projeto, porém muitas vezes é desconsiderada a realidade de uso. Já que o indivíduo pode ter uma visão diferente do produto em relação a do designer. Além disso, cada usuário estabelece relações afetivas relacionadas às interpretações subjetivas e efêmeras que muitas vezes não são possíveis serem planejadas, pois "os objetos se transformam, os sujeitos se modificam e os significados dos objetos para os objetos também se alteram" (BOMFIM, 1997, p.37).

Neste âmbito Sanches (2017) comenta que em um projeto de moda são estabelecidas soluções entre vestuário, corpo e ambiente que mediam interações físicas e subjetivas que podem gerar vínculos afetivos. Por fim, Sanches (2018, p.7) ressalta que a configuração da forma/vestuário é um sistema espacial composto por recursos estéticos e informacionais que se constrói por meio de uma superfície com materiais, cores, formas, silhuetas, texturas e circunda o espaço ocupado.

Para articular a figura/objeto e o objeto/espaço ocupado, é necessário compreender o sistema complexo dos objetos em relação objeto/sujeito. Neste contexto Bomfim 
(1997) apresenta categorias de complexidade do objeto para serem analisadas em relação aos aspectos objetivo/subjetivo dividindo- as em sete níveis; Objetivo, Bio-fisiológico, Psicológico, Sociológico, Natureza Cultural, Ideológica e Filosófica.

O nível objetivo está relacionado com os aspectos formais e visuais da figura como forma, textura, cor, volume entre outras dimensões. O bio-fisiológico é compreendido por meio dos órgãos sensoriais como: ver, ouvir e tocar, ou seja, estabelecem a realidade entre sujeito e objeto. $\mathrm{O}$ psicológico, leva em conta a subjetividade do usuário, "onde ocorrem as relações cognitivas, afetivas ou emocionais", que são determinadas pela individualidade, experiências pessoais e outros aspectos referentes a estética do objeto. O nível sociológico é quando o objeto ultrapassa sua funcionalidade e se torna simbólico. Já os níveis de natureza cultural, ideológica e filosófica dizem respeito aos valores empregados pelo usuário e das "diferentes condições em que o sujeito se reconhece no seu estar-no-mundo" (BOMFIM, 1997, p.39).

Portanto, a análise dos looks foram realizadas segundo estes níveis de Bomfim (1997), adotando uma abordagem qualitativa e descritiva. Dessa forma serão utilizadas as categorias de nível objetivo, bio-fisiológico, psicológico e sociológico, por se tratar de uma leitura segundo a recepção da mensagem visual e não como usuário do produto. Já os níveis de natureza cultural, ideológica e filosófica estão relacionados às crenças individuais de cada usuário e da experiência de uso do produto, por isso não serão analisadas. 
Figura 1: Primeiro look analisado

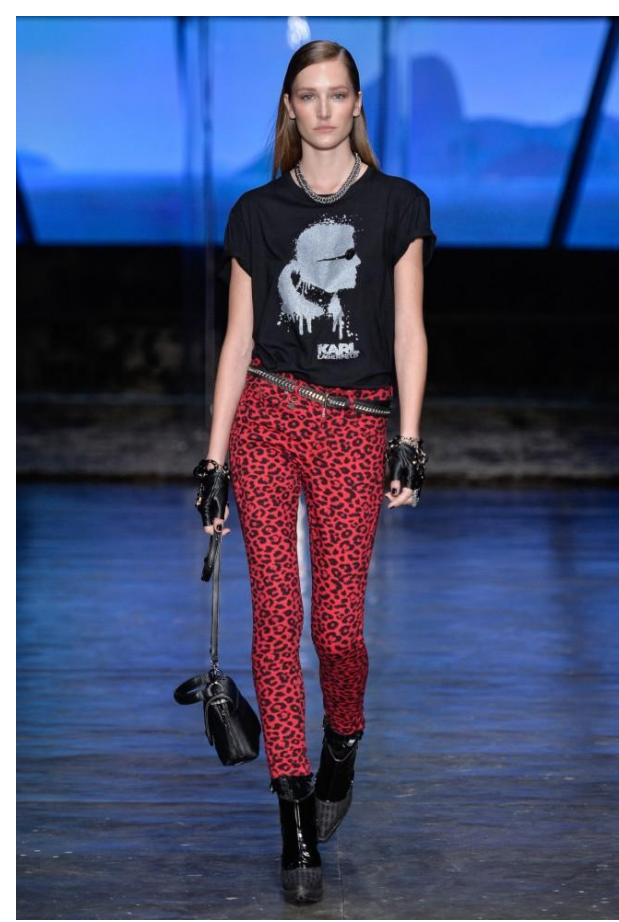

https://ffw.uol.com.br/desfiles/sao-paulo/verao-2017rtw/karl-lagerfeld-for-riachuelo/1582893/colecao/2/)

O primeiro look (Figura 1) em relação ao Nível Objetivo, é composto pela silhueta triângulo invertido, que segundo Dalbosco (2016) caracteriza- se quando o quadril é mais estreito que a parte superior do corpo. Outro ponto é a harmonia visual representados pela t-shirt e a calça skinning, através do contraste entre as cores preto, branco e vermelho.

No nível Bio-fisiológico, é possível verificar que a blusa preta é de malha de algodão e possui uma estampa aplicada com a técnica silkscreen, devido sua textura. A calça é modelo skinning, ou seja, ajustado ao corpo, com padrões de pintas de onça. Em relação aos acessórios, a modelo está com luvas, cinto, bota e bolsa na cor preta e um colar que remete a uma corrente. No geral, o look 1 apresenta conforto por ser composto por peças que os indivíduos usam com frequência em suas atividades diárias: calça ajustada e t-shirt. 
Já, no nível Psicológico o look 1 remete a uma jovem alta, moderna, confiante e cheia de atitudes. O estilo punk também é retratado, através das luvas, t-shirt, bota, cinto, correntes e predominância da cor preta. Em contrapartida, há nuances de um visual sexy, por conta da calça ajustada com estampada vermelha fazendo alusão a pele de uma onça. O salto alto e a bolsa tira colo.

No nível sociológico o grande destaque está na blusa que apresenta uma estampa com o perfil do estilista e a sua assinatura, transmitindo ao usuário um valor simbólico por usar um produto que traz referências visuais do karl Lagerfeld. Outro ponto são as luvas nada convencionais que complementam a estética do look 1 . Elas não possuem uma determinada funcionalidade, mas é um aspecto representativo do estilo do estilista.

Figura 2: Segundo look analisado.

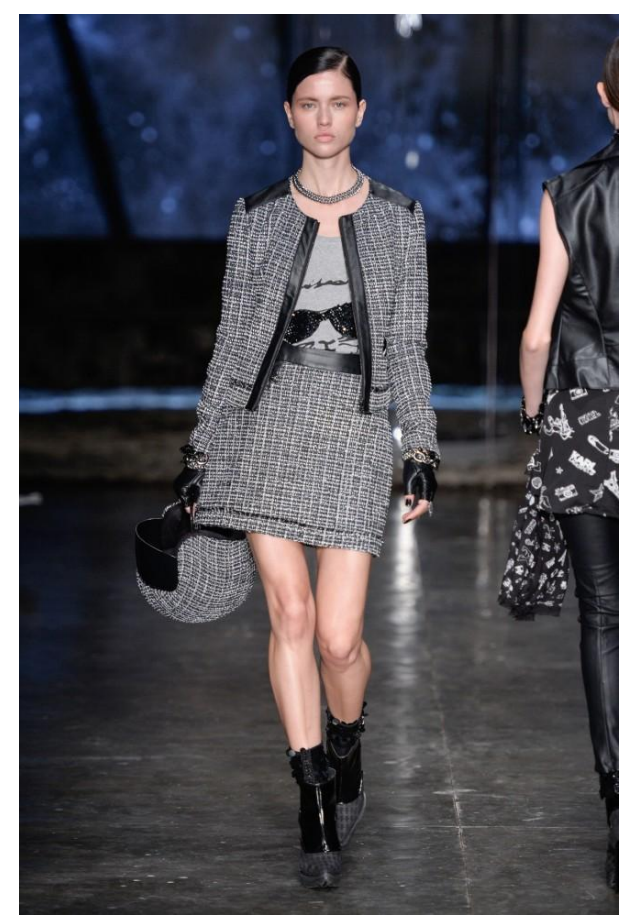

Fonte: https://ffw.uol.com.br/desfiles/sao-paulo/verao-2017rtw/karl-lagerfeld-for-riachuelo/1582893/colecao/21

O segundo look (Figura 2) em relação ao Nível Objetivo, apresenta a silhueta retângulo que segundo Dalbosco 
(2016), a medida do busto e quadril são semelhantes e, a cintura é pouco definida. É possível identificar esta característica na jaqueta e na saia. Já as cores que compõe os produtos são tons de preto, cinza e branco. Além disso, há uma simetria nos recortes do ombro, no transpasse em frente a jaqueta e nos detalhes em costura na barra da jaqueta e saia.

No nível Bio-fisiológico, verificou- se que o segundo look é composto por uma blusa cinza de malha, com estampa de um gato com óculos. Acredita- se que a técnica utilizada é o silkcreen por conta da nitidez do preto. Ainda, um conjunto de saia e jaqueta com tecido tweed que apresenta uma leve textura em sua padronagem. Além disso, há uma mistura de materiais têxteis na parte frontal da jaqueta, nos ombros e no cós da saia por meio de um couro fake. Novamente, são repetidos os elementos de estilo como; luvas, colar de corrente e bota preta. No geral, a jaqueta e a saia remetem a uma sensação de conforto e aquecimento devido às formas amplas e ao tecido. Já a t-shirt é uma peça que remete ao frescor devido a sua matéria prima, assim se tornando ideal para ser usada em dias de calor.

Em relação ao nível Psicológico a composição representa a uma jovem com estilo roqueiro devido a predominância de tons preto acinzentados. Além da jaqueta, saia, luva, bota com detalhes em couro. Por outro lado, há uma sofisticação por conta da repetição do tecido tweed, do colar com corrente e pontos de brilho e sapato de salto alto.

No nível sociológico ressalta- se na t-shirt, uma estampa de gato que traz referência afetiva do estilista por ser seu animal de estimação. Portanto, o usuário sentirá próximo ao criador por estar usando um símbolo fraterno. Outra característica é a sofisticação devido o tecido tweed e o conjunto de jaqueta e saia que se tornou um clássico nos 
produtos da marca Chanel, que atualmente são assinados por karl Lagerfeld.

Figura 3: Terceiro look analisado,

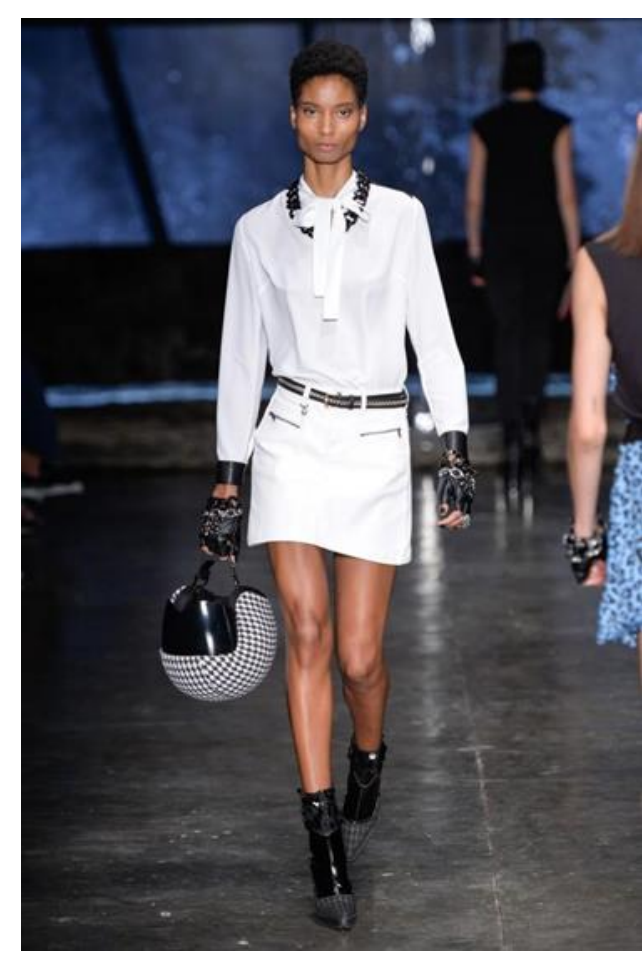

https://ffw.uol.com.br/desfiles/sao-paulo/verao-2017rtw/karl-lagerfeld-for-riachuelo/1582893/colecao/15/)

O terceiro look (Figura 3) em relação ao Nível Objetivo representa a mesma silhueta da figura 1 , triângulo invertido. Os ombros estão em ênfase devido um discreto volume nas mangas e nas laterais da camisa. Na cintura há um cinto preto que remete a um ajuste e para finalizar uma saia reta. A composição apresenta contraste entre as cores branco e preto. Além de simetria e equilíbrio entre os elementos da peça, como punhos da camisa, zíperes na saia e passante do cinto. Mas há uma assimetria em um metal que está localizado no lado direito do passante.

No nível Bio- fisiológico percebe- se que o look 3 é composto por uma camisa social de poliéster desconstruída, pois não apresenta transpasse com botões no centro frente, a gola foi estilizada por um laço e, o punho confeccionado com couro fake. Portanto há um contraste de texturas entre os materiais têxteis. Já, a saia branca possui um corte reto 
com detalhes em zíperes de metal e o tecido utilizado possivelmente é uma sarja, brim ou jeans. Os acessórios como colar, cinto e luvas apresentam detalhes com correntes, como nos outros dois looks (Figura 1 e 2) analisados e outros da coleção, a fim de compor uma harmonia visual. Por fim, a composição transmite uma sensação de calor devido a gola alta da camisa, a manga longa e as luvas. Entretanto, a saia equilibra esse desconforto, por ser uma peça muito utilizada em dias de calor.

Em relação ao no nível Psicológico é possível identificar uma jovem alta, magra, moderna com referências da estética rock devido a repetição de preto, do material têxtil que remete ao couro - nos punhos da camisa, luvas e cinto. Outra questão é a composição da saia com cós e passantes característicos de uma calça jeans e, os zíperes que vão de encontro aos padrões da estética urbana/casual. Porém, o look 3 (Figura 3) também transmite informações de clássico, devido a cor branca, a desconstrução da camisa social e o salto alto.

No nível sociológico observa- se que o look 3 apresenta a essência do estilo do criador, por meio da mistura de signos do estilo urbano/casual com clássico. Portanto, o usuário se sentirá especial por estar usando produtos semelhantes ao do estilista que são sinônimo de elegância e estilo.

\section{CONSIDERAÇÕES FINAIS}

A partir da análise realizada nos três looks da coleção Karl Lagerfeld for Riachuelo, pode se afirmar que os produtos observados possuem uma harmonia visual por meio da repetição de elementos que dialogam com a essência do estilo pessoal do estilista como as luvas, camisa, cores branca e preto além do símbolo afetivo como a estampa do seu gato de estimação. Desta forma, os looks 
contemplam os anseios do consumidor da contemporaneidade que buscam adquirir um produto que está associado com a imagem que procura transmitir e isso é possível devido os valores simbólicos contidos neles. Portanto, a parceria entre karl Lagerfeld e Riachuelo contemplam essas características por apresentar peças de vestuário que mostram além de sua funcionalidade e possibilitam a construção imagética objeto/indivíduo.

Por fim, é possível considerar que a aproximação de elementos do universo do estilista aos populares é uma forma de atender aos desejos dos consumidores. Com isso, fortalece a imagem do usuário nos grupos sociais, o estilista e a rede de lojas no mercado que transmite uma informação de alta moda ao seu público que antes era inacessível.

\section{REFERÊNCIAS}

BAUDRILLARD, Jean. O sistema dos Objetos. 5. ed. São Paulo: Perspectiva, 2008.

BOMFIM, Gustavo Amarante. Fundamentos de uma Teoria Transdisciplinar do Design: morfologia dos objetos de uso e sistemas de comunicação. Estudos em Design, Rio de Janeiro, v. 5, n. 2, p.27-41, dez. 1997.

BOMFIM, Gustavo A. Morfologia dos Objetos de Uso: uma contribuição para o desenvolvimento de uma teoria do design. Estudos em Design, Rio de Janeiro, p.9$18,1996$.

CARDOSO, Rafael. Design para um mundo complexo. São Paulo: Cosac Naify, 2012

DALBOSCO, Charlene Silva. A imagem corporal como geradora de atitudes. 2015. 433 f. Tese (Doutorado) Curso de Comunicação e Publicidade, Universitat Autònoma de Barcelona, Bellaterra, 2016.

DINIZ, Cláudio. O mercado do luxo no Brasil: tendência e oportunidades. São Paulo: Seoman, 2012. 
FEARTHERSTONE, Mike. Cultura de Consumo e PósModernismo. São Paulo: Studio Nobel, 1995.

Karl Lagerfeld for Riachuelo. Fashion for Ward. São Paulo, 26 de abril de 2016. Disponível em: <http://ffw.uol.com.br/desfiles/sao-paulo/verao-2017rtw/karl-lagerfeld-for-riachuelo/1582893/> Acesso em: 22 set. 2017.

MESSIAS, Elizete Menezes. Stella McCartney e Roberto Cavalli para C\&A: a construção do discurso da C\&A em torno de uma moda global acessível. Revista Dobras: Revista Dobras, São Paulo, v. 9, n. 19, p.146-162, jun. 2016.

MOURA, Mônica. Design e Arte no Contemporâneo: sentidos, estética e poéticas. Jundiaí: Paco Editorial, 2015a. Disponível em formato digital.

Singularidade e Diversidade no Design Contemporâneo Brasileiro. Paris: Anais EAD Universidade de Sorbonne, 2015b.

PASSARELI, Silvio. O universo do luxo: marketing e estratégia para o mercado de bens e serviços de luxo. São Paulo: Manole, 2010.

Riachuelo amplia aposta em grifes de luxo. Sociedade Brasileira de Varejo de Luxo. São Paulo, 26 de junho de 2016. Disponível em <http://sbvc.com.br/riachuelo-grifeluxo/> Acesso em: 2 de out. 2017.

SANCHES, Maria Celeste de Fátima. A Educação Projetual no Design de Moda: diretrizes pedagógicas. Revista de Ensino em Artes, Moda e Design, Florianópolis, v. 1, n. 2, p.9-28, maio 2018.

SANCHES, Maria Celeste de F. Moda e Projeto: estratégias metodológicas em design. São Paulo: Estação da Letras e Cores, 2017.

YACCOUB, Hilaine. A chamada "nova classe média": cultura material, inclusão e distinção social. Horizontes Antropológicos, Porto Alegre, v. 17, n. 36, p.197-231, dez. 2011.

FapUNIFESP(SciELO).

http://dx.doi.org/10.1590/s0104-71832011000200009. 